\title{
Does bronchial hyperresponsiveness predict a diagnosis of cough variant asthma in adults with chronic cough: a cohort study
}

\author{
Aleksandra Rybka-Fraczek, Marta Dabrowska* (10, Elzbieta M. Grabczak, Katarzyna Bialek-Gosk, \\ Karolina Klimowicz, Olga Truba and Rafal Krenke
}

\begin{abstract}
Bronchial hyperresponsiveness is a typical, but non-specific feature of cough variant asthma (CVA). This study aimed to determine whether bronchial hyperresponsiveness may be considered as a predictor of CVA in non-smoking adults with chronic cough (CC). The study included 55 patients with CC and bronchial hyperresponsiveness confirmed in the methacholine provocation test, in whom an anti-asthmatic, gradually intensified treatment was introduced. The diagnosis of CVA was established if the improvement in cough severity and cough-related quality of life in LCQ were noted.The study showed a high positive predictive value of bronchial hyperresponsiveness in this population. Cough severity and cough related quality of life were not related to the severity of bronchial hyperresponsiveness in CVA patients. A poor treatment outcome was related to a low baseline capsaicin threshold and the occurrence of gastroesophageal reflux-related symptoms. In conclusion, bronchial hyperresponsiveness could be considered as a predictor of cough variant asthma in non-smoking adults with CC.
\end{abstract}

Keywords: Asthma, Bronchial hyperresponsiveness, Cough

To the Editor

Cough variant asthma (CVA) is a phenotype of asthma, characterized by bronchial hyperresponsiveness (BHR) and cough as a sole symptom [1,2]. Despite some differences between the definitions of CVA, the presence of BHR and favorable response to anti-asthmatic treatment are two major criteria contributing to CVA diagnosis [35]. As CVA is a common cause of chronic cough (CC), the knowledge of its predictive factors is important for timely and effective diagnosis. Albeit BHR is a hallmark of CVA, its significance as a predictor of the response to classic anti-asthmatic therapy in adults with $\mathrm{CC}$ has not

*Correspondence: mdabrowska@mp.pl

Department of Internal Medicine, Pulmonary Diseases and Allergy,

Medical University of Warsaw, ul. Banacha 1A, 02-097 Warsaw, Poland been evaluated so far. Hence, the above was the aim of our study.

\section{Materials and methods \\ Study design, patients and definitions}

This prospective, single-center, observational study (ClinicalTrials.gov NCT03363698) was performed in the Department of Internal Medicine, Pulmonary Diseases and Allergy of the Medical University of Warsaw between 2016 and 2020 and included non-smoking adults with CC suspected to have CVA. The study protocol was approved by the Institutional Review Board (KB/222/2016) and all patients signed informed consent.

Inclusion criteria were as follows: (1) age 18-85 years, (2) CC (lasting $>8$ weeks), (3) no history of wheezing or dyspnea, (4) normal spirometry, (5) BHR in methacholine challenge [methacholine concentration causing 20\% fall in $\mathrm{FEV}_{1}\left(\mathrm{PC}_{20}\right)$ below $16 \mathrm{mg} / \mathrm{mL}$. Exclusion criteria original author(s) and the source, provide a link to the Creative Commons licence, and indicate if changes were made. The images or other third party material in this article are included in the article's Creative Commons licence, unless indicated otherwise in a credit line to the material. If material is not included in the article's Creative Commons licence and your intended use is not permitted by statutory regulation or exceeds the permitted use, you will need to obtain permission directly from the copyright holder. To view a copy of this licence, visit http://creativecommons.org/licenses/by/4.0/. The Creative Commons Public Domain Dedication waiver (http://creativeco mmons.org/publicdomain/zero/1.0/) applies to the data made available in this article, unless otherwise stated in a credit line to the data. 
included: (1) acute respiratory tract infection within the previous 6 weeks, (2) treatment with inhaled corticosteroids (ICS) or long-acting $\beta_{2}$-agonists (LABA) or leukotriene receptor antagonist (LTRA) or oral corticosteroids (OCS) or proton pump inhibitor (PPI) or antihistamine or intranasal corticosteroids within 4 weeks before enrollment, (3) abnormal chest radiograph, (4) active (within the last 12 months) smoking.

Upper airway cough syndrome (UACS) was defined as $\mathrm{CC}$ in a patient with chronic rhinitis or rhinosinusitis, diagnosed according to the respective guidelines [6-8]. Gastroesophageal reflux (GER) was diagnosed in patients who reported symptoms of GER or had a history of esophagitis revealed in upper gastrointestinal endoscopy or elevated number $(>73 / 24 \mathrm{~h})$ of reflux episodes registered in 24-h pH-impedance monitoring [9].

\section{Pulmonary function and BHR measurement}

All patients underwent pulmonary function testing, methacholine and capsaicin challenge as well as sputum induction before the onset of treatment. Spirometry was performed according to ERS guidelines (Lungtest 1000 MES, Krakow, Poland). FeNO was measured using Niox, Aerocrine, Solna, Sweden. Methacholine challenge was performed in a 2-min tidal breathing protocol (Lungtest 1000, MES Krakow, Poland), following the respective guidelines [10].

Capsaicin cough challenge was performed according to a previously recommended protocol using a single-breath method (Koko Digidoser, nSpire Health Inc., Longmont, USA) [9]. Cough reflex sensitivity was expressed as the lowest capsaicin concentrations evoking two (C2) and five (C5) coughs in the first $15 \mathrm{~s}$ after inhalation.

Sputum induction was performed as presented elsewhere [11].

\section{Treatment protocol and assessment of response}

Stepwise treatment protocol which included ICS, LABA, LTRA and OCS was applied in the study (see Fig. 1) [2, 5]. A significant response to treatment was defined as a decrease in cough severity from the baseline at least $20 \mathrm{~mm}$ [measured in visual analogue scale (VAS), range $0-100 \mathrm{~mm}]$ and improvement in quality of life (QoL) in Leicester Cough Questionnaire (LCQ, range 3-21) at least 1.3 points after one of three steps of therapy (Fig. 1) [9]. CVA was diagnosed if a patient met all inclusion criteria, did not meet any of the exclusion criteria and met the criteria of treatment response.

\section{Statistical analysis}

Statistical analysis was performed using Statistica 13.3 software package (StatSoft, Tulsa, USA). Data were presented as median and interquartile range or numbers and percentages. Nonparametric tests: the Mann-Whitney $U$ test, $\chi^{2}$ and Spearman rank's correlation were used to study the inter-group differences and correlations. A $P$ value lower than 0.05 was considered statistically significant.

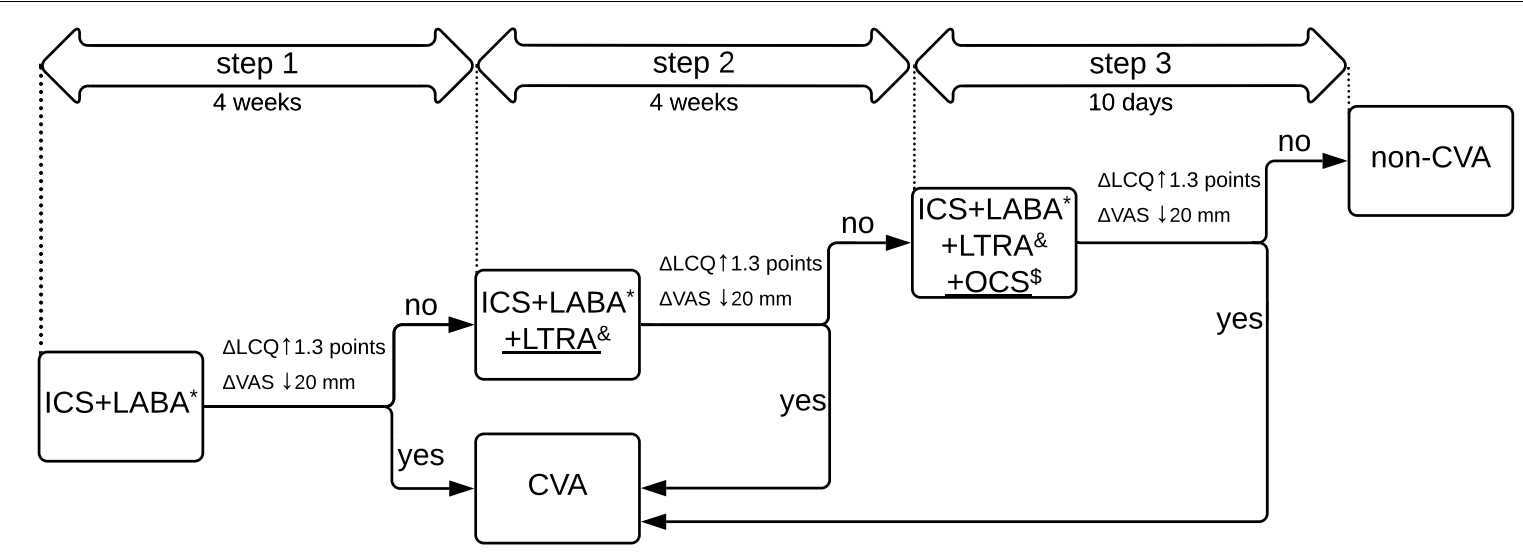

Fig. 1 Stepwise approach to treatment of patients with chronic cough and bronchial hyperresponsiveness. The protocol of treatment was based on an add-on approach and included three consecutive steps. Therapy was initiated with a combination of a moderate dose of ICS + LABA (formoterol). If the improvement was reported ( $\triangle \mathrm{LCQ}+1.3$ points and $\triangle \mathrm{VAS}-20 \mathrm{~mm}$ from the baseline) after 4 weeks of treatment, the patient was diagnosed with CVA. However, if cough persisted, step 2 was initiated with add-on LTRA (montelukast $10 \mathrm{mg}$ ), with measurement of LCQ and VAS after the next 4 weeks of treatment. In case of the treatment failure, a short course ( 10 days) of OCS ( $0.5 \mathrm{mg} / \mathrm{kg}$ of prednisone) was introduced. The diagnosis of CVA was established if the improvement was noted after any of three steps *moderate dose of ICS according to GINA (pMDI: beclometasone dipropionate HFA, extrafine particle or ciclesonide or budesonide) in combination with formoterol 12-24 mcg daily; ${ }^{\text {montelukast }}$ $10 \mathrm{mg}$ daily; ${ }^{\$}$ prednisone $0.5 \mathrm{mg} / \mathrm{kg}$ daily. CVA: cough variant asthma; GINA: The Global Initiative for Asthma; HFA: hydrofluoroalkane; ICS: inhaled corticosteroids; LABA: long-acting $\beta 2$-agonists; $\triangle \mathrm{LCQ}$ : change in Leicester cough questionnaire from the baseline; LTRA: leukotriene receptor antagonist; PMDI: pressurized metered-dose inhaler; OCS: oral corticosteroids; $\triangle V A S$ : change in cough severity from the baseline 


\section{Results}

\section{Study population and cough characteristics}

Fifty-five patients meeting the inclusion criteria were selected from 250 adults with CC managed in the cough center. The study was completed by 49 patients (2 patients were lost to follow-up and 4 discontinued the treatment). The baseline patients' characteristics are presented in Table 1. There was no correlation between $\mathrm{PC}_{20}$ and capsaicin cough provocation threshold.

\section{Treatment effects}

As $43 / 49$ (87.8\%) patients with CC and BHR responded to anti-asthmatic therapy, the positive predictive value (PPV) of BHR in establishing the diagnosis of CVA was $87.8 \%$. Almost three-quarters of patients (31/43) reported the improvement after ICS + LABA, 10/43 (23.3\%) after add-on LTRA and $2 / 43$ patients (4.6\%) improved after a short course of OCS. No clinical factors were identified to predict the response after each step of therapy.

\section{BHR and the response to therapy}

No correlation was found between $\mathrm{PC}_{20}$ and either change in VAS or LCQ score. There was a weak negative correlation between $\mathrm{PC}_{20}$ and body mass index (BMI) $(r=-0.36 \quad P=0.0117)$ and a significant difference between $\mathrm{BMI}$ in patients with marked/moderate BHR $(<1 \mathrm{mg} / \mathrm{mL})$ and mild/borderline BHR $(>1 \mathrm{mg} /$ $\mathrm{mL}): 33.2 \mathrm{~kg} / \mathrm{m}^{2}(30.2-35.3)$ vs. $27.4 \mathrm{~kg} / \mathrm{m}^{2}(24.4-31.4)$, $P=0.0040$; respectively.

Table 1 Patients' characteristics and comparison between patients with bronchial hyperresponsiveness who responded (CVA patients) and not responded (non-CVA patients) to anti-asthmatic therapy

\begin{tabular}{|c|c|c|c|c|}
\hline & All patients $(\mathrm{N}=49)$ & Non-CVA $(6 ; 12.2 \%)$ & CVA $(43 ; 87.8 \%)$ & $P$ value \\
\hline Age (years) & $60.0(54.0-68.0)$ & $54.5(45.0-56.0)$ & $61.0(55.0-69.0)$ & 0.0961 \\
\hline Gender (N female, \%) & $40(81.6 \%)$ & $5(83.3 \%)$ & $35(81.4 \%)$ & 0.6540 \\
\hline Cough duration (months) & $48.0(24.0-120.0)$ & $84.0(36.0-204.0)$ & $48.0(24.0-120.0)$ & 0.5190 \\
\hline Smoking status (N ex-smokers, \%) & $12(24.5 \%)$ & $0(0 \%)$ & $31(27.9 \%)$ & 0.3260 \\
\hline Blood eosinophil count (cells/uL) & $197.4(128.3-303.7)$ & $235.3(157.5-405.0)$ & $189.0(120.7-284.2)$ & 0.2578 \\
\hline $\mathrm{BMI}\left(\mathrm{kg} / \mathrm{m}^{2}\right)$ & $30.2(25.8-33.1)$ & $28.6(26.8-31.4)$ & $30.2(24.7-33.2)$ & 0.9878 \\
\hline $\mathrm{FEV}_{1}(\%$ predicted $)$ & $86.0(80.0-100.0)$ & $92.5(85.0-101.0)$ & $86.0(80.0-100.0)$ & 0.4453 \\
\hline FeNO (ppb) & $17.5(12.2-27.0)$ & $13.5(10.9-24.5)$ & $17.9(13.7-27.1)$ & 0.2891 \\
\hline $\mathrm{PC}_{20}(\mathrm{mg} / \mathrm{mL})$ & $2.0(0.8-4.4)$ & $2.2(0.7-3.2)$ & $2.0(0.8-5.0)$ & 0.6583 \\
\hline $\mathrm{PC}_{20}<1 \mathrm{mg} / \mathrm{mL}$ ( $\mathrm{N}$ patients, \%) & $14(28.6 \%)$ & $2(33.3 \%)$ & $12(27.9 \%)$ & 0.5590 \\
\hline $\mathrm{PC}_{20}<4 \mathrm{mg} / \mathrm{mL}$ ( $\mathrm{N}$ patients, \%) & $35(71.4 \%)$ & $5(83.3 \%)$ & $30(69.8 \%)$ & 0.4410 \\
\hline Sputum neutrophil percentage (\%) & $43.0(34.0-52.0)$ & $62.0(49.0-62.0)$ & $41.5(31.5-51.5)$ & 0.0291 \\
\hline Sputum eosinophil percentage (\%) & $1.0(0.0-4.0)$ & $0.0(0.0-3.0)$ & $1.0(0.0-4.0)$ & 0.5999 \\
\hline Atopy (N patients, \%) & $23(46.7 \%)$ & $2(33.3 \%)$ & $21(48.8 \%)$ & 0.7820 \\
\hline UACS (N patients, \%) & $38(77.6 \%)$ & $5(83.3 \%)$ & $33(76.7 \%)$ & 0.8730 \\
\hline GER (N patients, \%) & $27(55.1 \%)$ & $6(100 \%)$ & $21(48.8 \%)$ & 0.0183 \\
\hline Initial LCQ (points) & $10.4(8.4-13.1)$ & $9.9(9.1-10.9)$ & $10.7(8.3-13.8)$ & 0.6148 \\
\hline Change in LCQ due to treatment (points) & $4.8(2.2-6.2)$ & $1.8(0.2-3.6)$ & $4.9(3.1-6.5)$ & 0.0153 \\
\hline Initial VAS (mm) & $69.0(43.5-80.0)$ & $57.5(40.0-80.0)$ & $69.0(49.0-80.0)$ & 0.4729 \\
\hline Change in VAS due to treatment (mm) & $38.0(27.0-56.0)$ & $8.0(-15.0$ to 35.0$)$ & $41.0(27.0-58.0)$ & 0.0188 \\
\hline Initial capsaicin threshold C2 ( $\mu \mathrm{mol} / \mathrm{L})$ & $5.9(2.0-15.7)$ & $1.5(1.0-6.4)$ & $7.8(3.4-15.7)$ & 0.0338 \\
\hline Initial capsaicin threshold C5 ( $\mu \mathrm{mol} / \mathrm{L})$ & $7.8(3.9-15.7)$ & $5.9(2.4-19.5)$ & $7.8(3.9-15.7)$ & 0.4994 \\
\hline Final capsaicin threshold C2 ( $\mu \mathrm{mol} / \mathrm{L})$ & $3.9(2.0-15.7)$ & $1.0(0.5-1.0)$ & $5.9(3.9-15.7)$ & 0.0073 \\
\hline Final capsaicin threshold C5 ( $\mu \mathrm{mol} / \mathrm{L})$ & $7.8(3.9-15.7)$ & $1.0(1.0-3.9)$ & $11.7(3.9-15.7)$ & 0.0219 \\
\hline Change in the capsaicin threshold $C 2$ after treatment $(\mu \mathrm{mol} / \mathrm{L})^{\mathrm{a}}$ & $0(-1.5$ to 3.9$)$ & $-0.5(-6.9$ to 0$)$ & $0(0-3.9)$ & 0.1248 \\
\hline Change in the capsaicin threshold $C 5$ after treatment $(\mu \mathrm{mol} / \mathrm{L})^{\mathrm{a}}$ & $0(0-7.8)$ & $-6.8(-30.2$ to 0$)$ & $0(0-11.8)$ & 0.0466 \\
\hline
\end{tabular}

Data are presented as median and interquartile range or numbers and percentages. Statistical analysis included Mann-Whitney $U$ or $X^{2}$ test

CVA cough variant asthma, $B M I$ body mass index, $P C_{20}$ provocative concentration of methacholine causing $20 \%$ fall in FEV1, FeNO fractional exhaled nitric oxide, UACS upper airway cough syndrome, GER gastroesophageal reflux, $C 2$ the lowest capsaicin concentrations of capsaicin evoking two coughs, $C 5$ the lowest capsaicin concentrations of capsaicin evoking five coughs, LCQ Leicester Cough Questionnaire, VAS visual analogue scale

${ }^{a}$ Difference between final and baseline $\mathrm{C} 2 / \mathrm{C} 5$ threshold 

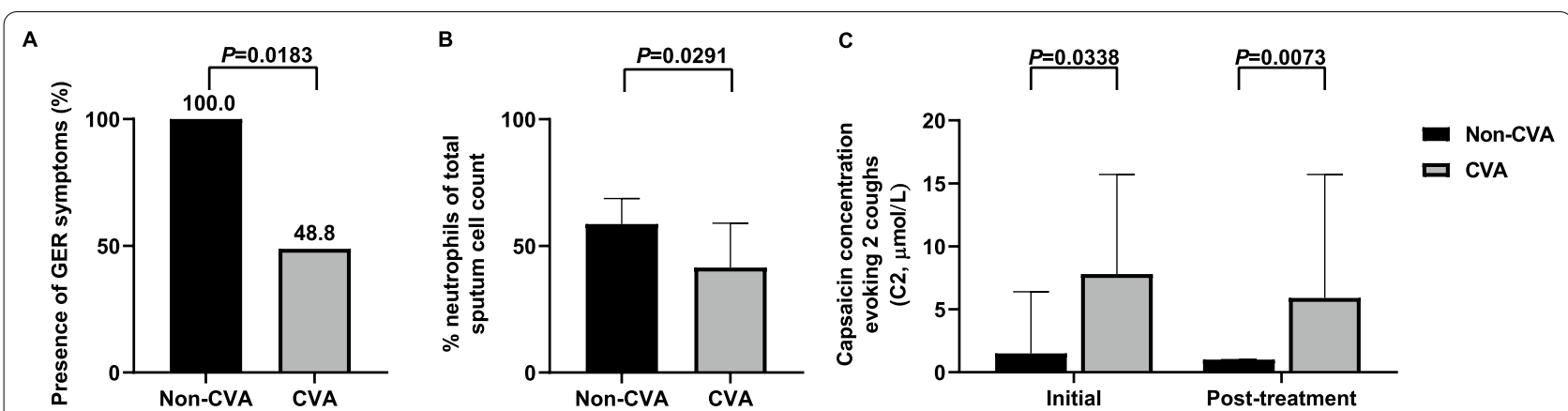

Fig. 2 Differences between patients with chronic cough without and with cough variant asthma. Data are presented as median and interquartile range or numbers and percentages. Statistical analysis included Mann-Whitney U or $X^{2}$ test. GER gastroesophageal reflux, CVA cough variant asthma, C2 the lowest capsaicin concentrations of capsaicin evoking two coughs

\section{Factors related to poor treatment outcome}

Patients who did not respond to the therapy, had lower capsaicin threshold (C2) in both, initial and post-treatment capsaicin provocation challenge $[1.5 \mu \mathrm{mol} / \mathrm{L}(1.0-$ 6.4) vs. $7.8 \mu \mathrm{mol} / \mathrm{L}(3.4-15.7), P=0.0338$ and $1.0 \mu \mathrm{mol} / \mathrm{L}$ (0.5-1.0) vs. $5.9 \mu \mathrm{mol} / \mathrm{L}$ (3.9-15.7), $P=0.0073$, respectively], more often reported symptoms of GER (100.0\% vs. $48.8 \%, P=0.0183)$ and had higher induced sputum neutrophil percentage [62\% (49.0-62.0) vs. 41.5\% (31.551.5), $P=0.0291$ ] (Fig. 2).

\section{Discussion}

This study demonstrated high PPV of BHR for the diagnosis of CVA in selected patients with CC suspected to have CVA. Most of these patients showed significant and rapid improvement already after the first-step treatment, i.e., a 4-week course of ICS and LABA. On the other hand, $12 \%$ of patients did not respond to treatment despite a high clinical probability of CVA. Low capsaicin threshold in cough challenge, symptoms of GER and high neutrophil percentage in sputum were related to poor response to treatment. The severity of BHR was related to BMI but was ineffective in the prediction of cough reduction after therapy.

To the best of our knowledge, there have been no previous studies on the response to anti-asthmatic therapy in CC adults with BHR. High PPV of BHR in CVA diagnosing in our study suggests that CVA should be considered as a major cause of cough in patients with $\mathrm{CC}$ presenting with BHR. Since the diagnosis of asthma is complex, there is no gold standard for its definition [12]. Therefore, there are few previous studies on the diagnostic value of BHR in classic asthma showing diverse PPV of BHR from 0.28 to 0.96 [13-15]. However, it should be mentioned that the assessment was made to diverse asthma diagnostic standards and targeted different groups. To the best of our knowledge, no study assessing the prevalence of CVA in patients with BHR has been published so far. Nevertheless, the analysis of patients with asthma, published by Sistek et al., revealed asthma diagnosis in over $42 \%$ with BHR and $C C$, which was lower than our results [14]. On the contrary, our data showing $87.8 \% \mathrm{PPV}$ of BHR in CVA seemed to be consistent with data for classic asthma published by Sumino et al., who showed PPV of BHR as high as $96 \%$ [15].

Interestingly, the severity of BHR was not the predictor of response to anti-asthmatic therapy. Furthermore, $\mathrm{PC}_{20}$ correlated negatively with $\mathrm{BMI}$, which is consistent with previous studies [16] and indicates the significance of obesity in the pathomechanism of CC. As upper airway diseases and gastroesophageal reflux (GER) are both common CC triggers in non-smoking adults and causes of BHR [17], we cannot assume that the presence of BHR in $\mathrm{CC}$ is the clear-cut diagnosis of CVA. In this study, all patients with BHR, who did not respond to anti-asthmatic therapy, presented symptoms of GER. It suggests that this population (non-smoking adults with CC, typical GER symptoms and BHR) needs more caution in establishing the diagnosis of CVA.

The results of our study support the opinion that asthmatic cough diagnosis and further decision making on continuation or discontinuation of anti-asthmatic treatment should be based on thorough and objective assessment of response to therapy in patients with suspicion of CVA. This approach is consistent with the recent guidelines $[1,2]$.

We are aware of several limitations in this study. Firstly, this was a single-center, observational analysis with a limited number of patients. Secondly, the results apply to a highly selected group of adults with $\mathrm{CC}$, without signs of wheezing and dyspnea, with normal spirometry and chest X-ray, in whom CVA was suspected. Thirdly, due to unavailability of the cough monitoring system, we used patient-reported outcomes rather than objective cough measures. 
In conclusion, due to its high PPV, BHR may be considered as a reliable predictor of CVA in non-smoking adults with CC.

\begin{abstract}
Abbreviations
BHR: Bronchial hyperresponsiveness; BMI: Body mass index; CC: Chronic cough; CVA: Cough variant asthma; C2: The lowest capsaicin concentrations of capsaicin evoking two coughs; $\mathrm{C} 5$ : The lowest capsaicin concentrations of capsaicin evoking five coughs; FeNO: Fractional exhaled nitric oxide; GER: Gastroesophageal reflux; ICS: Inhaled corticosteroids; LABA: Long-acting $\beta_{2}$-agonists; LCQ: Leicester Cough Questionnaire; $\triangle \mathrm{LCQ}$ : Change in Leicester Cough Questionnaire from the baseline; LTRA: Leukotriene receptor antagonist; OCS: Oral corticosteroids; PC $_{2}$ : Provocative concentration of methacho-

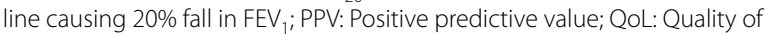
life; UACS: Upper airway cough syndrome; VAS: Visual analogue scale; $\triangle V A S$ : Change in visual analogue scale from the baseline.
\end{abstract}

\section{Acknowledgements}

The authors thank Katarzyna Mycroft, MD and Aleksandra Szubert-Franczak, MD for language editing.

Part of this work was presented at the 11 th International Cough Symposium, 21-22 January 2021.

\section{Authors' contributions}

Study design: ARF, MD, EMG, KBG, KK, OT, RK. Acquisition of data: ARF, MD, EMG, KBG, KK, OT. Statistical analysis: ARF, MD. Drafting: ARF, MD, RK. Interpretation, revisions, final approval, and accountability for accuracy and integrity: all authors. All authors read and approved the final manuscript.

\section{Funding}

This research has not received any specific financial support from public, commercial or not-for-profit funding bodies.

\section{Declarations}

Ethics approval and consent to participate

The study protocol was approved by the Institutional Review Board (KB/222/2016) and all patients signed informed consent.

\section{Consent for publication}

Not applicable.

\section{Competing interests}

ARF has received fee from Polpharma for attendance at ERS International Congress (2018), outside the submitted work; MD has received fees from Merck for lectures on chronic cough, outside the submitted work; EMG has received fee for lectures on chronic cough from Merck and Polpharma, outside the submitted work; RK has received fee for lectures from Chiesi, AstraZeneca, Polpharma outside the submitted work; Boehringer Ingelheim, Chiesi and AstraZeneca have covered his fee and travel expenses for ERS International Congresses $(2018,2019)$ and ATS Conferences $(2018,2019)$, outside the submitted work; the authors have no other relevant affiliations or financial involvement with any organization or entity with a financial interest in or financial conflict with the study apart from those disclosed.

Received: 6 June 2021 Accepted: 15 September 2021

Published online:

\section{References}

1. Morice AH, Millqvist E, Bieksiene K, Birring SS, Dicpinigaitis P, Domingo Ribas $C$, et al. ERS guidelines on the diagnosis and treatment of chronic cough in adults and children. Eur Respir J. 2020;55:1901136.
2. Cote A, Russell RJ, Boulet LP, Gibson PG, Lai K, Irwin RS, et al. Managing chronic cough due to asthma and NAEB in adults and adolescents: CHEST guideline and expert panel report. Chest. 2020;158:68-96.

3. Corrao WM, Braman SS, Irwin RS. Chronic cough as the sole presenting manifestation of bronchial asthma. N Engl J Med. 1979;300:633-7.

4. Nakamura Y, Tamaoki J, Nagase H, Yamaguchi M, Horiguchi T, Hozawa $\mathrm{S}$, et al. Japanese guidelines for adult asthma 2020. Allergol Int. 2020;69:519-48.

5. Global Initiative for Asthma. Global strategy for asthma management and prevention. 2021. https://ginasthma.org/wp-content/uploads/2021/04/ GINA-2021-Main-Report_FINAL_21_04_28-WMS.pdf. Accessed 01 May 2021.

6. Brozek JL, Bousquet J, Agache I, Agarwal A, Bachert C, Bosnic-Anticevich S, et al. Allergic rhinitis and its impact on asthma (ARIA) guidelines - 2016 revision. J Allergy Clin Immunol. 2017;140:950-8.

7. Hellings PW, Klimek L, Cingi C, Agache I, Akdis C, Bachert C, et al. Nonallergic rhinitis: position paper of the European Academy of Allergy and Clinical Immunology. Allergy. 2017;72:1657-65.

8. Fokkens WJ, Lund VJ, Mullol J, Bachert C, Alobid I, Baroody F, et al. European position paper on rhinosinusitis and nasal polyps 2012. Rhinol Suppl. 2012;23:1-298.

9. Morice AH, Fontana GA, Belvisi MG, Birring SS, Chung KF, Dicpinigaitis PV, et al. ERS guidelines on the assessment of cough. Eur Respir J. 2007:29:1256-76.

10. Crapo RO, Casaburi R, Coates AL, Enright PL, Hankinson JL, Irvin CG, et al. Guidelines for methacholine and exercise challenge testing-1999. Am J Respir Crit Care Med. 2000;161:309-29.

11. Paggiaro PL, Chanez P, Holz O, Ind PW, Djukanović R, Maestrelli P, et al. Sputum induction. Eur Respir J Suppl. 2002;37:3s-8s.

12. Cockcroft DW, Nair P. Methacholine test and the diagnosis of asthma. J Allergy Clin Immunol. 2012;130:556.

13. Jenkins MA, Clarke JR, Carlin JB, Robertson CF, Hopper JL, Dalton MF, et al. Validation of questionnaire and bronchial hyperresponsiveness against respiratory physician assessment in the diagnosis of asthma. Int J Epidemiol. 1996:25:609-16.

14. Sistek D, Wickens K, Amstrong R, D'Souza W, Town I, Crane J. Predictive value of respiratory symptoms and bronchial hyperresponsiveness to diagnose asthma in New Zealand. Respir Med. 2006;100:2107-11.

15. Sumino K, Sugar EA, Irvin CG, Kaminsky DA, Shade D, Wei CY, et al. Methacholine challenge test: diagnostic characteristics in asthmatic patients receiving controller medications. J Allergy Clin Immunol. 2012;130:69-75. e6.

16. Bates $\mathrm{JH}$. Physiological mechanisms of airway hyperresponsiveness in obese asthma. Am J Respir Cell Mol Biol. 2016;54:618-23.

17. Di Lorenzo G, Pacor ML, Mansueto P, Esposito Pellitteri M, Lo Bianco C, Ditta $V$, et al. Determinants of bronchial hyperresponsiveness in subjects with rhinitis. Int J Immunopathol Pharmacol. 2005;18:715-22.

\section{Publisher's Note}

Springer Nature remains neutral with regard to jurisdictional claims in published maps and institutional affiliations.

Ready to submit your research? Choose BMC and benefit from

- fast, convenient online submission

- thorough peer review by experienced researchers in your field

- rapid publication on acceptance

- support for research data, including large and complex data types

- gold Open Access which fosters wider collaboration and increased citations

- maximum visibility for your research: over 100M website views per year

At BMC, research is always in progress.

Learn more biomedcentral.com/submissions 